\title{
Ketamine for procedural pain relief in newborn infants
}

\author{
E Saarenmaa, P J Neuvonen, P Huttunen, V Fellman
}

\begin{abstract}
Aim-To assess the suitability of ketamine for relief of pain caused by tracheal suction during ventilator treatment in newborn infants.

Study design-In a randomised, double blind, cross over trial, 16 newborn infants received placebo or $0.5,1$, or $2 \mathrm{mg} / \mathrm{kg}$ ketamine as two minute infusions in random order five minutes before four separate endotracheal suctions, with intervals of at least 12 hours.
\end{abstract}

Results-Mean (SD) plasma ketamine concentration increased linearly with the dose (103 (49), 189 (75), and 379 (97) ng/ml after $0.5,1$, and $2 \mathrm{mg} / \mathrm{kg}$ respectively). Heart rate decreased significantly only after $2 \mathrm{mg} / \mathrm{kg}$ ketamine ( -7 (10) beats/min, $\mathbf{p}=0.029 v$ placebo). The increases in heart rate, arterial blood pressure, and pain score in response to tracheal suction during the placebo phase (11 (23) beats/ $\min , \mathrm{p}=0.065 ; 6$ (7) $\mathrm{mm} \mathrm{Hg}, \mathrm{p}=0.004 ; 3.5$ (interquartile range (IQR) 2.75-5) points, $p=0.001$ ) were not attenuated by 0.5 or 2 $\mathrm{mg} / \mathrm{kg}$ ketamine. However, $1 \mathrm{mg} / \mathrm{kg}$ ketamine attenuated the increase in pain score (1 (IQR 0.75-4.25) points, $p=0.043 v$ placebo), but not in heart rate (7 (23) beats/min) or blood pressure $(7$ (9) $\mathrm{mm}$ Hg).

Conclusion-None of the doses of ketamine attenuated the changes in heart rate or blood pressure caused by suction, and only with a dose of $1 \mathrm{mg} / \mathrm{kg}$ was the suction induced pain moderately reduced. Thus infusion of ketamine at the doses used appears to be an ineffective method of relieving the pain caused by endotracheal suction.

(Arch Dis Child Fetal Neonatal Ed 2001;85:F53-F56)

Keywords: preterm; tracheal suction; ketamine; pain relief

Department of Clinical Pharmacology, University of Helsinki

P J Neuvonen

Department of Forensic Medicine, University of Oulu, Finland

P Huttunen

Correspondence to: Dr Saarenmaa, Hospital for Children and Adolescents, University of Helsinki, PB 281, 00029 Huch, Finland elina.saarenmaa@hus.fi

Accepted 7 February 2001 without pain relief. This may lead to stimulation of the autonomic nervous and neuroendocrine systems and therefore the risk of deleterious haemodynamic changes and hypoxaemia in response to unrelieved pain. ${ }^{5}$ There is thus a need for easily administrable short acting analgesia with no respiratory depressant effect for procedures in the neonatal period.

In our previous trial, endotracheal suction was found to be a painful procedure according to the behavioural pain scale and cardiovascular criteria used. ${ }^{6}$ Alfentanil at a dose of 20 $\mu \mathrm{g} / \mathrm{kg}$ relieved pain, but caused a high rate of rigidity and is therefore suitable only with muscle relaxant in the neonatal period. ${ }^{6}$ Ketamine is a dissociative anaesthetic agent, with analgesic effects at subanaesthetic plasma concentrations. ${ }^{7}$ Experimental and clinical studies have shown that it has few cardiovascular effects and is only a minor respiratory depressant. Thus it may also be suitable for procedural pain relief in the neonatal period.

As only a few studies have been carried out on the analgesic use of ketamine during the neonatal period, ${ }^{89}$ we designed this randomised trial to evaluate its suitability and the appropriate dose for relief of the brief discomfort and pain caused by tracheal suction in newborn infants during the recovery period of ventilator treatment when sedation or analgesia is usually avoided.

\section{Patients and methods}

The study was performed in the neonatal intensive care unit of the Hospital for Children and Adolescents, University of Helsinki. The protocol was approved by the ethics committee of the hospital and the Finnish National Agency for Medicines. Written informed consent from the parents was obtained before enrolment.

Intubated and mechanically ventilated newborn infants were eligible if the gestational age was 24 weeks or more, no chromosomal aberrations or major anomalies were suspected, an indwelling arterial line for continuous blood pressure monitoring and blood sampling had been inserted on clinical indications, and no continuous analgesic medication was given.

Sixteen infants (10 boys, six girls) with a mean (SD) birth weight of 1466 (588) g and a gestational age of 31 (3) weeks were enrolled. Nine infants had been delivered by caesarean section, and seven vaginally. The Apgar score was 6 (3) at one minute and 6 (2) at five minutes. The umbilical artery $\mathrm{pH}$ was $7.2(0.1)$ at birth. All 16 infants completed the protocol. The age of the infants at enrolment in the trial 
was 3 (2) days. The main diagnosis was respiratory distress syndrome in 12 infants, infection in three, and persistent pulmonary hypertension of the neonate in one. One patient developed necrotising enterocolitis, and one developed grade IV intraventricular haemorrhage during the study period. Four infants received dopamine and/or dobutamine; 12 infants received surfactant and 12 indomethacin during the study period. One infant died at the age of 3 weeks as the result of severe asphyxia and intraventricular haemorrhage.

The study had a randomised, double blind, crossover design. Each patient received saline as placebo and three different doses of ketamine, $0.5,1$, and $2 \mathrm{mg} / \mathrm{kg}$, intravenously in random order before four painful procedures. Routine tracheal suction was chosen as a standard painful procedure. One nurse diluted ketamine from commercial vials (Ketalar; Parke-Davis) according to the randomised instructions in sealed numbered envelopes. An equal volume $(0.5 \mathrm{ml} / \mathrm{kg})$ was infused for all doses. The solution was administered over two minutes by another nurse unaware of the content in the syringe. The tracheal suction was started five minutes later, and the severity of the pain and discomfort was assessed during the procedure by the blinded researcher (ES). The infant was bag ventilated during the procedure, and, if oxygen desaturation occurred, the $\mathrm{FIO}_{2}$ was increased.

The time interval between the doses was at least 12 hours. Arterial blood was sampled (1 $\mathrm{ml}$ blood in EDTA vials containing $15 \mu \mathrm{l} 1 \%$ sodium metabisulphite) before the solution was administered and 10 minutes after the suction for determination of plasma adrenaline (epinephrine) and noradrenaline (norepinephrine) concentrations. Simultaneous blood samples $(0.5 \mathrm{ml})$ were obtained for the determination of plasma ketamine concentration. The samples were centrifuged and stored at $-70^{\circ} \mathrm{C}$ until analysed. The volume of blood withdrawn was replaced with packed red cells according to clinical practice for samples drawn on clinical indications.

Heart rate, mean arterial blood pressure, and oxygen saturation were continuously monitored (Hewlett Packard Neonatal Component Monitoring System). Maximal changes within five minutes of the administration of the solution investigated and in association with the endotracheal suction were registered. Pain responses before, during, and after tracheal suction were registered blindly using a behavioural pain score ranging from zero to eight developed from the Children's Hospital of East Ontario Pain Scale (CHEOPS) ${ }^{10}$ and Neonatal Infant Pain Scale (NIPS). ${ }^{11}$

Plasma adrenaline and noradrenaline concentrations were measured by high pressure liquid chromatography (HPLC) ${ }^{12}$ The detection limit of the assay was $0.23 \mathrm{nmol} / 1$. Plasma ketamine concentrations were determined by HPLC using etidocaine as an internal standard. ${ }^{13}$ The limit of quantification was $20 \mathrm{ng} / \mathrm{ml}$, and the day to day coefficient of variation was $6.5 \%$ at $196 \mathrm{ng} / \mathrm{ml}(\mathrm{n}=5)$.
Paired Student's $t$ test and Wilcoxon signed rank test were used for statistical analysis. A p value less than 0.05 was regarded as significant. Data are presented as mean (SD) or $(95 \%$ confidence interval $(95 \% \mathrm{CI})$ ) or as median (interquartile range (IQR)). The sample size required was estimated to be 16 according to a power calculation in which we expected that the ketamine would decrease the mean pain score from 5 to 2 (3), similar to the effect observed in our previous trial with alfentanil. ${ }^{6}$ The calculation was based on a $5 \%$ significance level and $80 \%$ power.

\section{Results}

The plasma ketamine concentration, measured 15 minutes after the infusion, increased linearly with the dose (table 1). Six infants, who received placebo as their second, third or fourth dose, still had detectable ketamine concentrations 12 hours after the previous ketamine dose.

The median (IQR) heart rate was 148 (139159) beats/min and blood pressure 44 (40-49) $\mathrm{mm} \mathrm{Hg}$ before drug administration. Table 2 gives the maximal ketamine induced changes in the heart rate and blood pressure within five minutes of the injection. Only after administration of $2 \mathrm{mg} / \mathrm{kg}$ ketamine did the heart rate decrease significantly $(p=0.029$; to 145 (9) beats $/ \mathrm{min}$ ) compared with placebo. There were no significant changes in the arterial blood pressure after any of the ketamine doses. Blood pressure and heart rate increased as the result of endotracheal suction after all four doses (table 3). The suction induced changes were not significantly attenuated by any of the doses of ketamine.

Table 1 Plasma ketamine concentrations 15 minutes after an intravenous dose

\begin{tabular}{ll}
\hline Dose $(\mathrm{mg} / \mathrm{kg})$ & Concentration $(\mathrm{ng} / \mathrm{ml})$ \\
\hline 0.5 & $103(49)(73$ to 134$)$ \\
1 & $189(75)(144$ to 235$)$ \\
2 & $379(97)(320$ to 437$)$ \\
\hline
\end{tabular}

Values are mean (SD) (95\% confidence interval).

Table 2 Maximal changes in heart rate and mean arterial blood pressure in 16 infants within five minutes of receiving placebo and three different doses of ketamine as premedication in random order

\begin{tabular}{lcc}
\hline Dose $(\mathrm{mg} / \mathrm{kg})$ & $\begin{array}{l}\text { Heart rate change } \\
\text { (beats } / \mathrm{min})\end{array}$ & $\begin{array}{l}\text { Blood pressure change } \\
(\mathrm{mm} \mathrm{Hg})\end{array}$ \\
\hline Placebo & $3(-4$ to 9$)$ & $0(-2$ to 3$)$ \\
0.5 & $0(-7$ to 7$)$ & $4(1$ to 6$)$ \\
1 & $1(-11$ to 13$)$ & $1(-3$ to 5$)$ \\
2 & $-7(-12 \text { to } 1)^{\star}$ & $-1(-4$ to 2$)$ \\
\hline
\end{tabular}

Values are mean of the difference ( $95 \%$ confidence interval). ${ }^{\star} \mathrm{p}<0.05$ compared with placebo.

Table 3 Maximal changes in heart rate and mean arterial blood pressure caused by repeated endotracheal suction in 16 infants receiving placebo and three different doses of 16 infants receiving placebo and three different
ketamine as premedication in random order

\begin{tabular}{lll}
\hline $\begin{array}{l}\text { Dose } \\
(\mathrm{mg} / \mathrm{kg})\end{array}$ & $\begin{array}{l}\text { Heart rate change } \\
\text { (beats } / \mathrm{min})\end{array}$ & $\begin{array}{l}\text { Blood pressure } \\
\text { change }(\mathrm{mm} \mathrm{Hg})\end{array}$ \\
\hline Placebo & $11(-1$ to 23$)$ & $6(2$ to 10$) \dagger$ \\
0.5 & $12(3 \text { to } 21)^{\star}$ & $6(0 \text { to } 11)^{\star}$ \\
1 & $7(-5$ to 19$)$ & $7(2$ to 13$) \dagger$ \\
2 & $19(10$ to 28$) \dagger$ & $9(3$ to 14$) \dagger$ \\
\hline \multicolumn{2}{l}{ Values are mean of the difference $(95 \%$ confidence interval). }
\end{tabular}

${ }^{\star} \mathrm{p}<0.05,+\mathrm{p}<0.01$ compared with presuction values. 


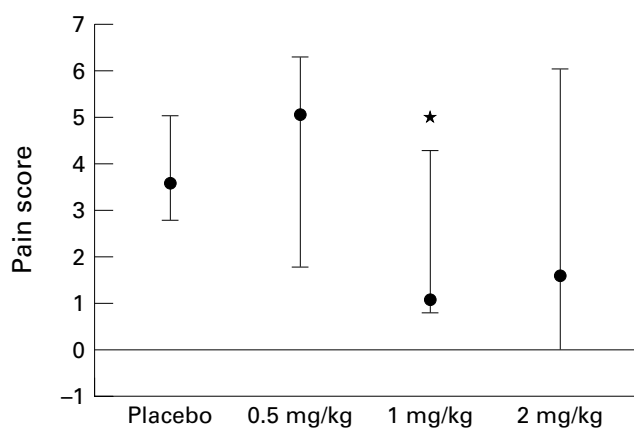

Figure 1 Changes in behavioural pain score (median (IQR)) caused by suction after placebo and the three doses of ketamine. ${ }^{*} p=0.043$ compared with placebo.

The increase in the pain score caused by the suction, from a median baseline level of 0 (IQR $0-3)$, was significant $(\mathrm{p}=0.001)$ after placebo (fig 1). A similar increase was found after the ketamine doses of $0.5 \mathrm{mg} / \mathrm{kg}(\mathrm{p}=0.001)$ and 2 $\mathrm{mg} / \mathrm{kg}(\mathrm{p}=0.004)$. Only after $1 \mathrm{mg} / \mathrm{kg}$ was an attenuation of the pain score change found $(p=0.043)$ compared with placebo.

The changes in plasma catecholamine concentrations were, if any, minor (table 4).

\section{Discussion}

Endotracheal suction of mechanically ventilated children and adults is considered to be a painful and unpleasant procedure and thus performed with premedication. Even though newborn infants cannot express their pain, this procedure can also be considered painful for them and used as a model of standardised pain stimulus. ${ }^{61415}$ We have recently studied the analgesic efficacy of opioids in neonates using this technique. ${ }^{6}{ }^{16}$

In previous studies in adults, an analgesic effect has been observed with plasma ketamine concentrations of $150 \mathrm{ng} / \mathrm{ml}$ after intramuscular administration and $40 \mathrm{ng} / \mathrm{ml}$ after oral administration. ${ }^{17}$ In the present study, plasma ketamine concentration increased linearly with the dose. With intravenous ketamine doses of 1 and $2 \mathrm{mg} / \mathrm{kg}$, plasma ketamine levels corresponded to those reported to produce satisfactory analgesia. ${ }^{17}$ However, the analgesic effect achieved was inadequate. Tracheal suction caused a significant increase in the pain score from the baseline during all four treatments. Significant attenuation of pain was noticed only with the $1 \mathrm{mg} / \mathrm{kg}$ dose compared with placebo but not with the $2 \mathrm{mg} / \mathrm{kg}$ dose. This poor dose-effect relation is somewhat surprising. Ketamine is lipophilic and therefore rapidly distributed to the tissues; the maximal analgesic effect may therefore have been reached before tracheal suction-that is, during the three minute interval between the end of infusion and the start of suction. The lack of expected improvement in analgesic effect with increasing dose may also be explained by unpleasant side effects of ketamine. This speculation is based on the fact that the most worrying adverse effect of ketamine is the so called psychic emergence phenomenon, described as a combination of vivid dreams, hallucinations, excitement, and delirium. ${ }^{18}$ The occurrence of psychomimetic side effects in infants is difficult to assess, but we cannot exclude this reason for unsatisfactory pain relief with the largest dose. At least theoretically, some potential side effects of ketamine (nystagmus, hypertonus of skeletal musculature, and muscle movement) may confound assessment of the pain score in newborn infants, although this scoring method has been used successfully to show the analgesic effects of opioids, for instance, even in extremely premature infants. ${ }^{6} 16$

The cardiovascular effects of ketamine were minor in the present study. The heart rate decreased only after administration of $2 \mathrm{mg} / \mathrm{kg}$ ketamine, and there were no statistically or clinically significant changes in blood pressure after any doses of ketamine. In a previous study, in which 10 preterm infants, aged 1-10 days, received $5 \mathrm{mg} / \mathrm{kg}$ ketamine intravenously before central venous catheterisation, a significant but short lasting decrease in arterial blood pressure was observed two minutes after ketamine administration, but no changes in cerebral blood flow occurred. ${ }^{9}$ A moderate decrease in arterial blood pressure was also observed in another study in which 202 week old preterm infants received $2 \mathrm{mg} / \mathrm{kg}$ ketamine intravenously before surgical procedures. ${ }^{19} \mathrm{~A}$ dose of $1 \mathrm{mg} / \mathrm{kg}$ ketamine given intravenously caused no appreciable changes in heart rate and blood pressure in 25 infants aged less than 3 months. $^{20}$

Increased plasma catecholamine concentrations have been used as indicators of pain and stress during surgery in newborn infants. ${ }^{12122}$ Increased catecholamine levels have been reported during suctioning ${ }^{23}$ and are considered clinically relevant indicators of pain and distress. ${ }^{24-26}$ Although ketamine acts as a myocardial depressant in isolated heart preparations in vitro, studies on term infants and older children have shown an increase in heart rate, cardiac output, and arterial blood pressure as the result of a central effect and the release of noradrenaline. However, in this study, no clear effect of ketamine or the procedure was found, and a slight but significant increase in plasma noradrenaline was seen only

Table 4 Plasma catecholamine concentrations (mean (SD)) before and after endotracheal suction and their changes (mean of the difference with $95 \%$ CI)

\begin{tabular}{|c|c|c|c|c|c|c|}
\hline \multirow[b]{2}{*}{ Dose $(\mathrm{mg} / \mathrm{kg})$} & \multicolumn{3}{|c|}{ Adrenaline (nmol/l) } & \multicolumn{3}{|c|}{ Noradrenaline (nmol/l) } \\
\hline & Before & After & Change & Before & After & Change \\
\hline Placebo & $0.9(0.8)$ & $0.8(0.6)$ & $0.1(-0.3$ to 0.6$)$ & $4.3(2.5)$ & $4.7(2.4)$ & $-0.5(-2.0$ to 1.1$)$ \\
\hline 0.5 & $1.5(0.9)$ & $0.6(0.5)^{\star}$ & $0.8(0.3$ to 1.3$)$ & $4.7(3.1)$ & $4.3(2.0)$ & $0.5(-0.8$ to 1.7$)$ \\
\hline 1 & $0.9(0.7)$ & $0.6(0.6)$ & $0.2(-0.2$ to 0.7$)$ & $4.1(3.4)$ & $4.9(4.1)$ & $-0.8(-1.9$ to 0.2$)$ \\
\hline 2 & $0.8(0.6)$ & $0.9(0.5)$ & $0.0(-0.4$ to 0.4$)$ & $3.9(1.9)$ & $5.4(2.8)^{\star}$ & $-1.6(-3.1$ to 0.0$)$ \\
\hline
\end{tabular}

${ }^{\star} \mathrm{p}<0.05$ compared with presuction values. 
after the highest dose $(2 \mathrm{mg} / \mathrm{kg})$ of ketamine. This may be because, in critically ill infants exposed to prolonged stress, the response to both ketamine, thought to induce catecholamine release from endogenous sources, ${ }^{27}$ and the stress of suction is diminished.

In conclusion, intravenously administered ketamine in the dose range $0.5-2.0 \mathrm{mg} / \mathrm{kg}$ during the first few days of life had only a small or moderate analgesic effect on the pain caused by endotracheal suction. Therefore ketamine at the doses used may not be suitable for procedural pain relief in newborn infants, despite the advantages of virtually no respiratory depressant effect and little influence on cerebral blood flow. ${ }^{9}$

This study was supported by grants from the Finnish Pediatric Research Foundation. We thank Martti Virtanen, MD, PhD for
statistical guidance and Olli Meretoja, MD, PhD for anaesthesiological advice.

1 Anand KJS, Sippel WG, Aynsley-Green A. Randomised trial of fentanyl anaesthesia in preterm babies undergoing surgery. Lancet 1987;i:243-8.

2 Marlow N, Weindling AM, van Peer A, et al. Alfentanil pharmacokinetics in preterm infants. Arch Dis Child 1990;65:349-51.

3 Choonara I. Management of pain in newborn infants. Semin Perinatol 1992;16:32-40.

4 Anderson CTM, Zeltzer LK, Fanurik D. Procedural pain. In: Schechter NL, Berde CB, Yaster M, eds. Pain in infants, children, and adolescents. Baltimore: Williams \& Wilkins, 1993:435-58.

5 Hickey PR, Hansen DD, Wessel DL, et al. Blunting of stress responses in the pulmonary circulation of infants by fentanyl. Anesth Analg 1985;64:1137-42.

6 Saarenmaa E, Huttunen P, Leppäluoto J, et al. Alfentanil as procedural pain relief in newborn infants. Arch Dis Child 1996;75:F103-7.

7 Reich DL, Silvay G. Ketamine: an update on the first twenty-five years of clinical experience. Can $\mathcal{F}$ Anaesth twenty-five years

8 Hartvig P, Larsson E, Joachimsson P-O. Postoperative analgesia and sedation following pediatric cardiac surgery using a constant infusion of ketamine. $\mathcal{F}$ Cardiothorac Vasc Anesth 1993;7:148-53.

9 Betremieux P, Carre P, Pladys P, et al. Doppler ultrasound assessment of the effects of ketamine on neonatal cerebra circulation. Dev Pharmacol Ther 1993;20:9-13.

10 McGrath PJ, Johnson G, Goodman JT, et al. CHEOPS: A behavioral scale for rating postoperative pain in children.
In: Fields HL, Dubner R, Cervero F, eds. Advances in pain therapy. New York: Raven Press, 1985;9:395-402.

11 Lawrence J, Alcock D, McGrath P, et al. The development of a tool to assess neonatal pain. Neonatal Netw 1993;12:5966

12 Eriksson BM, Persson BA. Determination of catecholamines in rat heart and plasma samples by liquid chromatography with electrochemical detection. f Chromatogr 1982;228:143-54.

13 Adams HA, Weber B, Bachmann M B, et al. The simultaneous determination of ketamine and midazolam using high ous determination of ketamine and midazolam using high thetist 1992;41:619-24.

14 Skov L, Ryding J, Pryds O, et al. Changes in cerebral oxygenation and cerebral blood volume during endotracheal suctioning in ventilated neonates. Acta Paediatr 1992;81:389-93.

15 Perlman JM, Volpe JJ. Suctioning in the preterm infant: effects on cerebral blood flow velocity, intracranial pressure and arterial blood pressure Pediatrics 1983;72:329-34.

16 Saarenmaa E, Huttunen P, Leppäluoto J, et al. Advantages of fentanyl over morphine in analgesia for ventilated newborn infants after birth: a randomized trial. 7 Pediatr 1999;134:144-50.

17 Grant IS, Nimmo WS, McNicol LR, et al. Pharmacokinetics and analgesic effects of IM and oral ketamine. Brf Anaesth 1981;53:805-10.

18 White PF, Walter LW, Anthony JT. Ketamine: its pharmacology and therapeutic uses. Anesthesiology 1982:56;11936.

19 Friesen RH, Henry DB. Cardiovascular changes in preterm neonates receiving isoflurane, halothane, fentanyl, and ketamine. Anesthesiology 1986;64:238-42.

20 Tashiro C, Matsui Y, Nakano S, et al. Respiratory outcome in extremely premature infants following ketamine anaesthesia. Can F Anaesth 1991;38:287-91.

21 Anand KJS, Brown MJ, Bloom SR, et al. Studies on the hormonal regulation of fuel metabolism in the human newborn infant undergoing anaesthesia and surgery. Horm Res 1985;22:115-28.

22 Anand KJS, Phil D, Hansen DD, et al. Hormonal-metabolic stress responses in neonates undergoing cardiac surgery. Anesthesiology 1990;73:661-70.

23 Greisen G, Frederiksen PS, Hertel J, et al. Catecholamine response to chest physiotherapy and endotracheal suctioning in preterm infants. Acta Paediatr Scand 1985;74:525-9.

24 Quinn MW, Otoo F, Rushforth JA, et al. Effect of morphine and pancuronium on the stress response in ventilated preterm infants. Early Hum Dev 1992;30:241-8.

25 Quinn MW, Wild J, Dean HG, et al. Randomised double-blind controlled trial of effect of morphine on catecholamine concentrations in ventilated pre-term babies. Lancet 1993;342:324-7.

26 Jacqz-Aigrain E, Daoud P, Burtin P, et al. Placebocontrolled trial of midazolam sedation in mechanically ventilated newborn babies. Lancet 1994;344:646-50.

27 Takki S, Nikki P, Jäättelä A, et al. Ketamine and plasma catecholamines. Br f Anaesth 1972:44;1318-21. 